\title{
Integration of Asphaltenes Flocculation Modeling into Athos Reservoir Simulator
}

\author{
E. Béhar ${ }^{1}$, P. Mougin ${ }^{1}$ and A. Pina ${ }^{1}$ \\ 1 Institut français du pétrole, 1 et 4, avenue de Bois-Préau, 92852 Rueil-Malmaison Cedex - France \\ e-mail: emmanuel.behar@ifp.fr - pascal.mougin@ifp.fr - annabelle.pina@ifp.fr
}

\begin{abstract}
Résumé - Intégration d'un modèle de floculation des asphaltènes dans le simulateur de gisement Athos - Afin de répondre aux besoins croissants d'études de simulation de gisements pour de nombreuses applications, il a été considéré nécessaire d'intégrer un modèle de floculation des asphaltènes dans le progiciel Athos.

Athos est un simulateur versatile qui propose un large choix d'options différentes de la physique des phénomènes étudiés.

Les compagnies opératrices souhaitent disposer d'outils prédictifs, leur permettant de planifier la production d'un gisement, quand le brut asphalténique qu'il contient est susceptible d'induire une réduction de sa porosité et de sa perméabilité. Ces compagnies peuvent ainsi planifier des technologies de maintien de pression afin d'éviter les risques liés à la floculation des asphaltènes initialement dissous dans le brut.

Dans le cas des gisements en mer profonde, les conséquences économiques de telles stratégies peuvent être de toute première importance.

Le travail présenté ici décrit des procédures qui ont été implantées dans le progiciel Athos afin de permettre le calcul des conditions de floculation des asphaltènes. Il est ainsi possible de déterminer les quantités de dépôts d'asphaltènes au cours des différentes phases du développement d'un gisement ou d'un champ. Ceci conduira évidemment à mieux connaître la réduction de porosité et de perméabilité consécutive à la floculation des asphaltènes, et par conséquent, à une évaluation plus fiable de la production du brut.
\end{abstract}

\footnotetext{
Abstract - Integration of Asphaltenes Flocculation Modeling into Athos Reservoir Simulator - To respond to the ever-growing needs of reservoir simulation studies in a large range of applications, it has been considered necessary to integrate an asphaltenes flocculation model into the Athos software.

Athos is a multipurpose simulator which provides a lot of different physical options.

Operating companies wish to have available predictive tools, allowing them to plan a reservoir production when the asphaltenic crude it contains could induce porosity and permeability reduction. These companies can thus plan pressure maintenance technologies in order to avoid risks related to asphaltenes flocculation out of the reservoir crude.

In the case of deep offshore reservoirs, the economic consequences of such strategies can be of primary importance.

The work presented here describes procedures which have been implemented in order to compute asphaltene flocculation conditions within the Athos software. It is thus possible to determine the amount of asphaltenes deposit at different stages of a reservoir or of a field development. This would obviously improve the knowledge of porosity and permeability variation as a result of asphaltenes flocculation, and thus lead to a more reliable evaluation of the oil production.
} 


\section{LIST OF SYMBOLS}

CME constant mass expansion

DD differential depletion

GC gas chromatography

HPLC high performance liquid chromatography

$P \quad$ pressure

$P_{b} \quad$ bubble pressure

$P_{f} \quad$ flocculation threshold

$P_{R} \quad$ initial reservoir pressure

$T$ temperature

$v_{\text {rel }} \quad$ "crude + gas" relative volume

$v_{\text {tot }} \quad$ "crude + gas" total volume.

\section{INTRODUCTION}

Exploitation of deep water and marginal fields is frequently complicated by the possibility of deposition of solids during production, mainly of asphaltenes. These can reduce productivity significantly and even cause loss of some wells.

Production of hydrocarbons from deep water offshore fields is a costly and difficult process due to severe conditions and high operational costs. A deep offshore horizontal well may cost over $30 \mathrm{M} €$ and in the worst case, the unexpected occurrence of organic solids is known to have lead to a complete loss of some wells.

In the case where wells have been kept flowing, the estimated production loss resulting from asphaltenes deposition amounts to $20-30 \%$ because of shut-in and deposit removal procedures.

That is why operating companies wish to have available predictive tools, allowing them to plan a reservoir production when the asphaltenic crude it contains could induce porosity and permeability reduction, or wells and surface facilities plugging. These companies can thus plan pressure maintenance technologies in order to avoid risks related to asphaltenes flocculation out of the reservoir crude.

We have seen above that in the case of deep offshore reservoirs, the economic consequences of such strategies can be of primary importance.

In order to respond to the ever-growing needs of reservoir simulation studies in a large range of applications, the work described hereafter has been to integrate an asphaltenes flocculation model into the Athos software.

Athos is a multipurpose simulator (Magras et al., 2001). It provides a lot of different physical options from the most routinely used (black-oil, multicomponent) to the more specialized ones (thermal, polymer injection, steam injection, etc.).

To predict the operating conditions which induce asphaltenes flocculation out of reservoir crudes, a compositional thermodynamic model has been proposed by Szewczyk and Behar (1999). We describe hereafter the procedures which have been implemented in order to compute asphaltene flocculation conditions within the Athos software.

\section{OUTLINE OF THE FLOCCULATION MODEL}

The main assumption on which this model has been built is that flocculation corresponds to a thermodynamic transition of asphaltenes from a first liquid phase, the crude, to a second liquid phase, the asphaltenic deposit. The proportion and the composition of each of these phases are computed by a single flash calculation, performed with the translated equation of state of Peng and Robinson, associated with the group contribution mixing rules of Abdoul and Péneloux (Péneloux et al., 1989; Abdoul, 1991).

The Peng and Robinson equation of state can be written under the form of the generalized cubic equation:

$$
P=\frac{R T}{v-b}-\frac{a(T)}{v(v+\gamma b)}
$$

with:

$P$ the pressure

$T$ the temperature

$v$ the molar volume

$R$ the ideal gas constant

$\gamma$ is a parameter depending on the equation of state to be selected; for the Peng and Robinson one, its value is equal to 4.82843 . Therefore this cubic equation has two parameters: the attractive term $a(T)$ and the covolume $b$.

For a pure compound, the attractive term is a function of critical temperature, critical pressure and acentric factor whereas the covolume depends only on critical properties.

The same equation of state is also used for mixtures, the attractive and covolume terms being then expressed by the following relations:

$$
\begin{gathered}
b=\sum x_{i} b_{i} \\
\frac{a(T, x)}{b(T)}=\sum x_{i} \frac{a_{i}(T)}{b_{i}}-E(T, x)
\end{gathered}
$$

In these equations, $x_{i}$ is the molar fraction of each compound $i$. The excess function $E$ is composed of two terms. The first one is obtained from a groups contribution method and the second one is a function of the lengths of the molecules.

In conclusion, the used equations need the knowledge of the critical characteristics and of the molecular structure of each compound present in the studied mixture in order to determine its parameters. The analytical representation of a crude oil according to the procedure described hereafter allows us to obtain the necessary information.

This analytical representation of the crude consists of (Fig. 1):

- a light fraction $\mathrm{C}_{10-}$ made of 29 pure components $\left(\mathrm{N}_{2}\right.$, $\mathrm{CO}_{2}$ and hydrocarbons corresponding to the three main chemical families: normal and iso-alkanes, naphthenes and aromatics); 


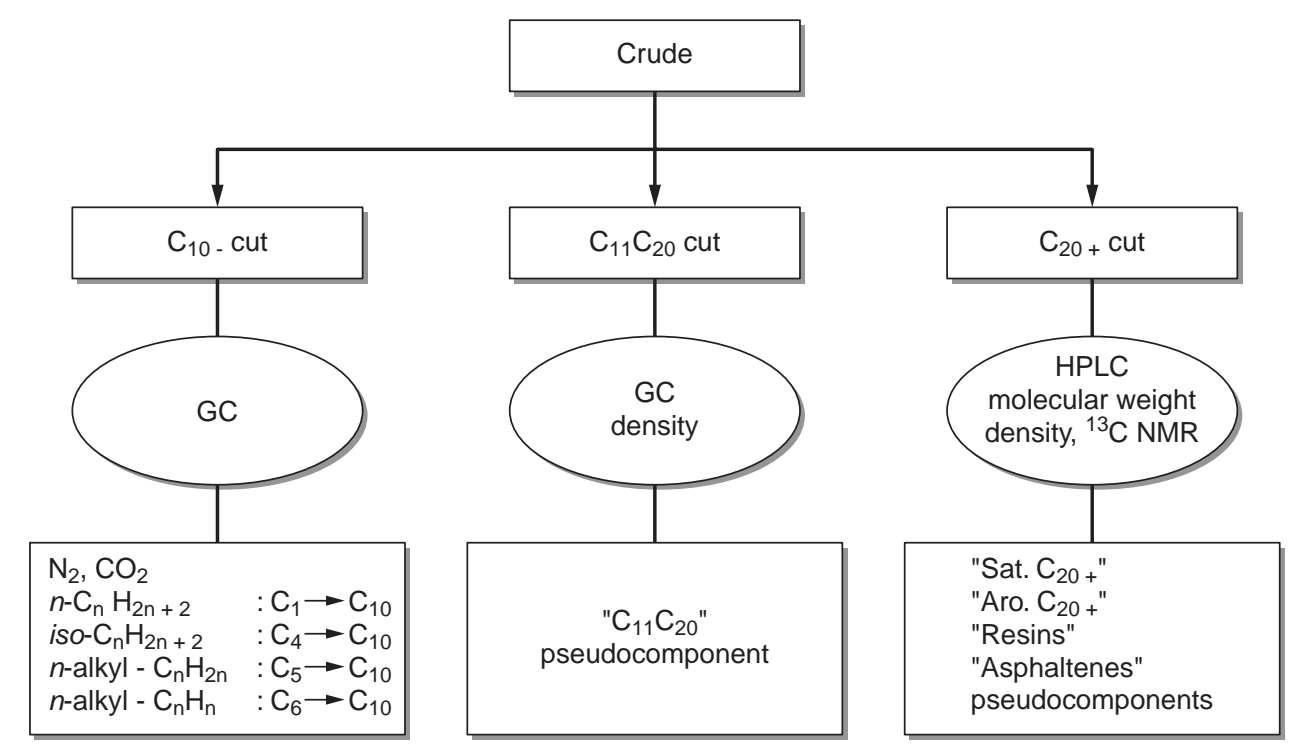

Figure 1

Analytical representation of a crude as an input to the compositional flocculation model (Szewczyk and Béhar, 1999).

- an intermediate fraction made of a pseudocomponent $\mathrm{C}_{11}$ $\mathrm{C}_{20}$;

- a heavy end made of four pseudocomponents: $\mathrm{C}_{20+}$ saturates, $\mathrm{C}_{20+}$ aromatics, resins and asphaltenes.

The physical characteristics of these pure or pseudocomponents, needed by any equation of state based thermodynamic model, are taken from the following sources:

- Reid et al. (1987), data for the pure components up to $\mathrm{C}_{10}$;

- the API Technical Data Book (1983) correlations for the $\mathrm{C}_{11} \mathrm{C}_{20}$ pseudocomponent for which its molecular weight (given by the GC analysis) and density are needed;

- the group contribution methods proposed by Avaullée (1996) and by Rogalski and Neau (1990) for the four heavier pseudocomponents, the data needed for these methods being the molecular weight, the density and the ${ }^{13} \mathrm{C}$ NMR which have been measured for these fractions. The ${ }^{13} \mathrm{C}$ NMR information is used to give an average structure of the four heavy (end) fractions in terms of groups contribution.

Table 1 gives an example of the main information used as an input to the phase equilibrium model.

With the assumption (regarding flocculation) mentioned above, the possible split of any crude at a given set of reservoir pressure and temperature conditions can lead to the following phases at thermodynamic equilibrium:

- if $P>$ flocculation threshold $P_{f}$ and $P>$ bubble pressure $P_{b}$, then only one liquid phase exists;

- if $P>P_{b}$ and $P<P_{f}$, then two liquid phases exist (the crude and the asphaltenic deposit);

- if $P<P_{f}$ and $P<P_{b}$, then three phases coexist (the gas, the crude and the deposit).

\section{FITTING OF THE FLOCCULATION MODEL PARAMETERS}

As no thermodynamic model is predictive, a computing procedure has been proposed (Szewczyk and Béhar, 1999) in order that the calculated results are in agreement with a set of experimental data which characterizes both the PVT as well as the flocculation properties of a given reservoir crude. These properties are the following:

- The relative volumes measured during a constant composition/mass depletion at a temperature selected between the reservoir and the separator values:

$$
v_{\text {rel }}(T, P)=\frac{v_{\text {tot }}(T, P)}{v_{b}\left(T, P_{b}\right)}
$$

In this relation, $v_{\text {tot }}$ is the volume of the whole fluid in $T$ and $P$ conditions while $v_{b}$ is the liquid volume at the same temperature but at its bubble pressure. In such experiments, the crude bubble pressure $P_{b}$ at a fixed temperature corresponds to the change of slope of the relative volume curve versus pressure. We can also limit ourselves to using the bubble pressure for the parameters fitting (if the volumetric data are not available).

- The measured evolution with pressure of the amount of asphaltenes still dissolved in the crude after flocculation during a depletion at the same temperature selected for the previous experiment.

If the constant mass/composition depletion is a standard procedure in PVT laboratories, the measured evolution of the amount of dissolved asphaltenes with pressure is more unusual. Such measurements are carried in an equipment made of an equilibrium cell associated to a filtration device. 
TABLE 1

Example of a studied crude oil (Szewczyk and Béhar, 1999)

\begin{tabular}{|c|c|c|c|c|c|}
\hline Compound & $\begin{array}{c}\text { Weight fraction } \\
(\%)\end{array}$ & $\begin{array}{l}\text { Molecular weight } \\
\qquad(\mathrm{g} / \mathrm{mol})\end{array}$ & $\begin{array}{c}T_{c} \\
(\mathrm{~K})\end{array}$ & $\begin{array}{c}P_{c} \\
\text { (bar) }\end{array}$ & $\omega$ \\
\hline $\mathrm{N}_{2}$ & 0.11 & 28.013 & 126.2 & 33.9 & 0.039 \\
\hline $\mathrm{CO}_{2}$ & 1.15 & 44.010 & 304.1 & 73.8 & 0.239 \\
\hline methane & 7.18 & 16.043 & 190.4 & 46.0 & 0.011 \\
\hline ethane & 2.29 & 30.070 & 305.4 & 48.8 & 0.099 \\
\hline propane & 2.45 & 44.094 & 369.8 & 42.5 & 0.153 \\
\hline$n$-butane & 1.33 & 58.124 & 425.2 & 38.0 & 0.199 \\
\hline iso-butane & 0.68 & 58.124 & 408.2 & 36.5 & 0.183 \\
\hline$n$-pentane & 0.46 & 72.151 & 469.7 & 33.7 & 0.251 \\
\hline iso-pentane & 0.52 & 72.151 & 460.4 & 33.9 & 0.227 \\
\hline alcanes $\mathrm{C}_{6}$ & 0.05 & 86.178 & 497.5 & 30.1 & 0.278 \\
\hline naphthenes $\mathrm{C}_{5}$ & 0.01 & 70.135 & 511.7 & 45.1 & 0.275 \\
\hline$n$-hexane & 0.46 & 86.178 & 507.5 & 30.1 & 0.299 \\
\hline alcanes $\mathrm{C}_{7}$ & 0.14 & 100.205 & 535.3 & 28.1 & 0.323 \\
\hline naphthenes $\mathrm{C}_{6}$ & 0.21 & 84.162 & 532.7 & 37.8 & 0.231 \\
\hline aromatics $\mathrm{C}_{6}$ & 0.03 & 78.114 & 562.2 & 48.9 & 0.212 \\
\hline$n$-heptane & 0.32 & 100.205 & 540.3 & 27.4 & 0.349 \\
\hline alcanes $\mathrm{C}_{8}$ & 0.48 & 114.232 & 561.7 & 25.4 & 0.259 \\
\hline naphthenes $\mathrm{C}_{7}$ & 0.53 & 98.198 & 572.2 & 34.7 & 0.236 \\
\hline aromatics $\mathrm{C}_{7}$ & 0.21 & 92.141 & 591.8 & 41.0 & 0.263 \\
\hline$n$-octane & 0.29 & 114.232 & 568.8 & 24.9 & 0.398 \\
\hline alcanes $\mathrm{C}_{9}$ & 0.59 & 128.242 & 587.0 & 23.1 & 0.423 \\
\hline naphthenes $\mathrm{C}_{8}$ & 0.76 & 112.216 & 609 & 30.0 & 0.243 \\
\hline aromatics $\mathrm{C}_{8}$ & 0.51 & 106.168 & 617.2 & 36.0 & 0.302 \\
\hline n-nonane & 0.34 & 128.259 & 594.6 & 22.9 & 0.445 \\
\hline alcanes $\mathrm{C}_{10}$ & 0.83 & 142.286 & 613.7 & 21.4 & 0.490 \\
\hline naphthenes $\mathrm{C}_{9}$ & 0.97 & 126.243 & 639.0 & 28.0 & 0.258 \\
\hline aromatics $\mathrm{C}_{9}$ & 0.78 & 120.195 & 631.1 & 32.1 & 0.326 \\
\hline$n$-decane & 0.36 & 142.286 & 617.7 & 21.2 & 0.489 \\
\hline $\mathrm{C}_{11} \mathrm{C}_{20}$ & 23.09 & 193 & 738.6 & 21.0 & 0.5563 \\
\hline $\mathrm{C}_{20+}$ sat. & 18.40 & 380.0 & 832.9 & 0.1763 & 0.9121 \\
\hline $\mathrm{C}_{20+}$ aro. & 20.64 & 500.0 & 952.0 & 0.1601 & 1.1591 \\
\hline $\mathrm{C}_{20+}$ res. & 10.87 & 800.0 & 1041.1 & 0.1545 & 1.4607 \\
\hline $\mathrm{C}_{20+}$ asph. & 2.96 & 1000.0 & 1112.2 & 0.1544 & 1.7201 \\
\hline
\end{tabular}

The desired pressure and temperature are fixed in the cell and a small amount of the crude is pushed through the filtration device. The flocculated asphaltenes are then retained on the filter. The filtrate is further flashed at atmospheric pressure to produce a gas and a liquid. The asphaltenes content in the liquid phase is measured by $n$-heptane titration. The flocculated asphaltenes are then obtained from a mass balance.

Figures 2 and 3 illustrate the experimental procedures used for the determination of these data as well as the obtained results.

Coming now to the fitting procedure, it consists in the following steps:

- First, the critical temperature of the " $\mathrm{C}_{11} \mathrm{C}_{20}$ " pseudocomponent is determined by matching at best the computed and experimental crude relative volumes versus pressure (or the bubble pressure).
- Next, the "asphaltenes" molecular weight as well as their critical temperature are determined for an optimal calculation of the amount of asphaltenes still dissolved in the crude after flocculation.

- In addition, the critical pressures of the five "heavy" pseudocomponents " $\mathrm{C}_{11} \mathrm{C}_{20}$ " up to "Asphaltenes" are determined for an accurate computation of their density at ambient temperature and atmospheric pressure. These densities are either measured or assumed on the basis of independent measurements (i.e., the density of the asphaltenes pseudocomponent is taken to be $1.2 \mathrm{~g} / \mathrm{cm}^{3}$ ).

Tables 2 and 3 show examples of the fitted results. Table 2 compares the "predicted" and the final value for the " $\mathrm{C}_{11}$ $\mathrm{C}_{20}$ " fraction. Table 3 gives the same information for the asphaltenes fraction. 


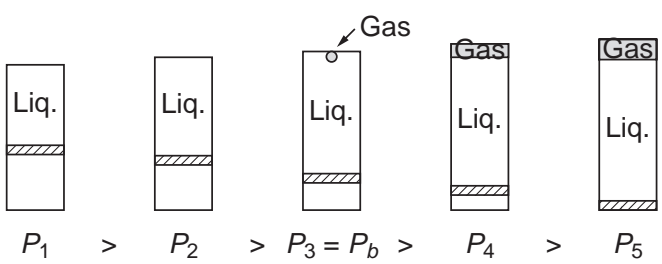

TABLE 2

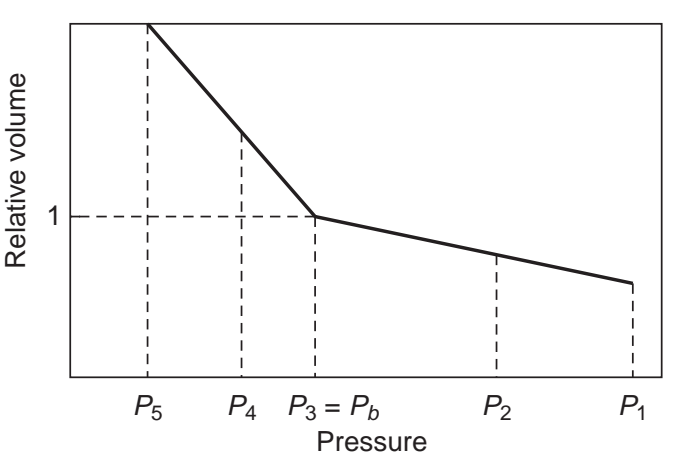

Figure 2

Experimental procedure for the measurement of the bubble pressure and the relative volumes during a constant mass/ composition depletion.

Fitting of the $\mathrm{C}_{11} \mathrm{C}_{20}$ fraction parameters

\begin{tabular}{c|c|c}
\hline & $T_{c}(\mathrm{~K})$ & $P_{c}(\mathrm{bar})$ \\
\hline "Predicted" & 738.6 & 20.92 \\
\hline Fitted & 628.40 & 18.61 \\
\hline
\end{tabular}

TABLE 3

Fitting of the $\mathrm{C}_{20}+$ asphaltenes fraction parameters

\begin{tabular}{c|c|c|c}
\hline & $M$ & $T_{C}(\mathrm{~K})$ & $P_{C}(\mathrm{bar})$ \\
\hline "Predicted" & 1000.0 & 1112.2 & 0.1544 \\
\hline Fitted & 654.16 & 1413.50 & 12.81 \\
\hline
\end{tabular}

Figures 4 and 5 show a comparison between the data measured for the crude whose composition is given in Table 1 and the same data computed with the model which has been described above.

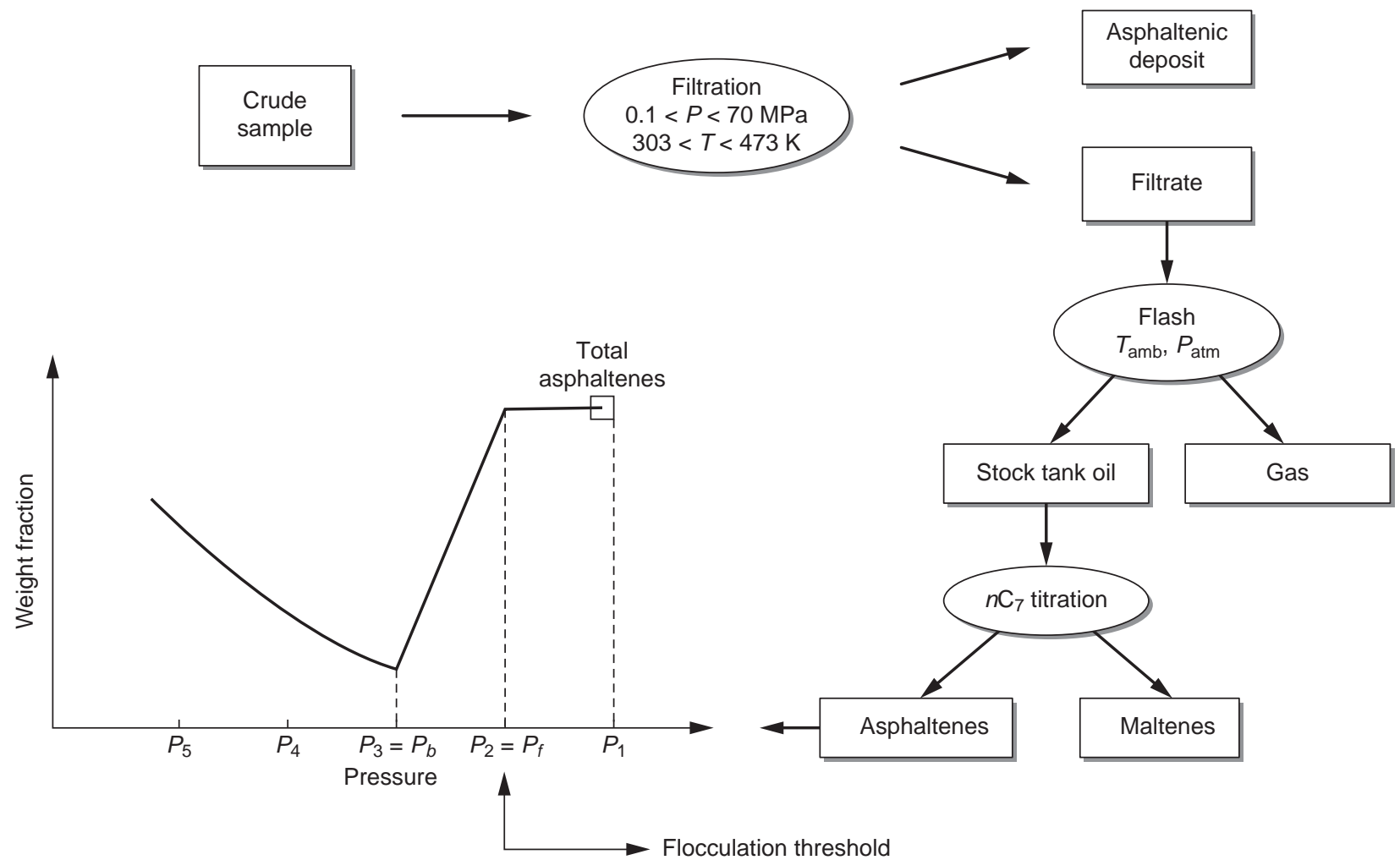

Figure 3

Experimental procedure for the measurement of the amount of flocculated asphaltenes during a depletion. 


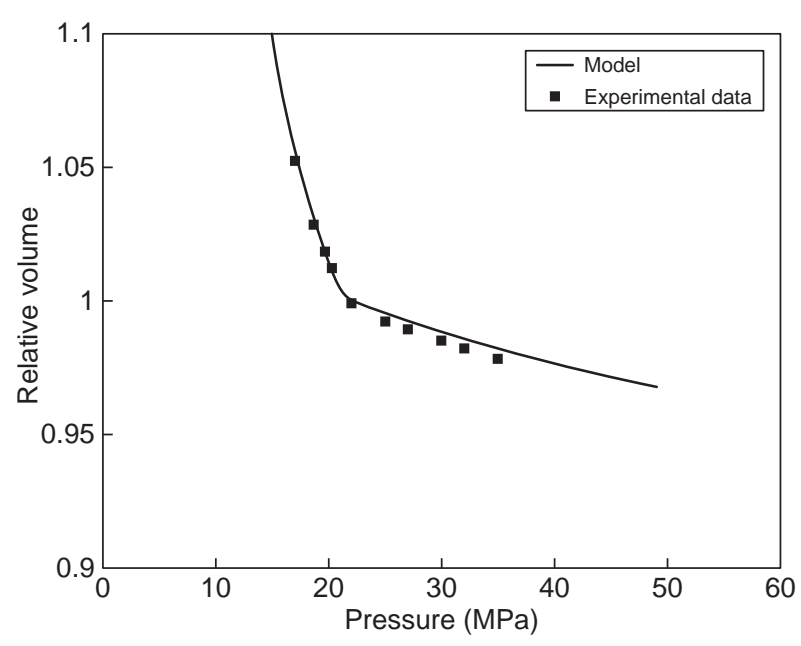

Figure 4

Comparison between measured and computed relative volumes versus pressure during a constant mass/composition depletion.

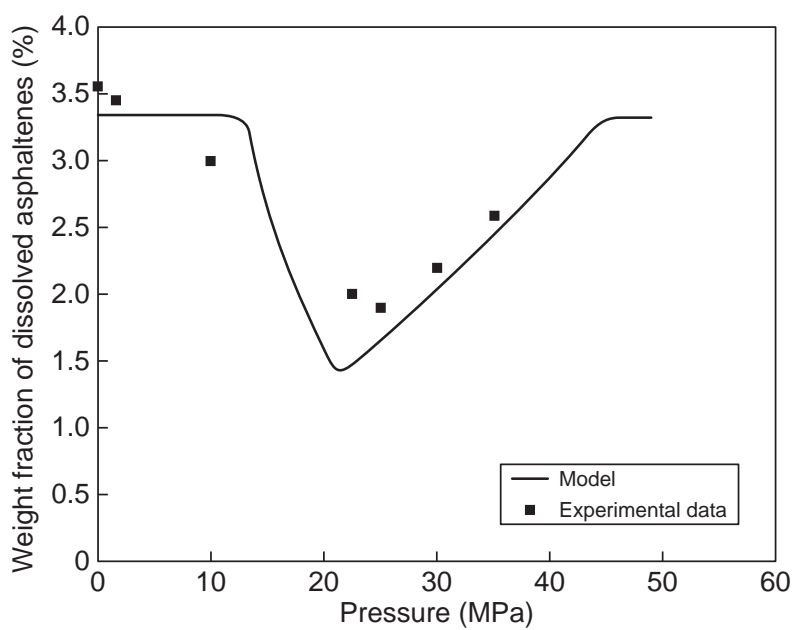

Figure 5

Comparison between measured and computed weight fraction of asphaltenes still dissolved in the crude versus pressure during a depletion.

\section{APPLICATION OF THE FLOCCULATION MODEL TO RESERVOIR SIMULATION}

With the help of the flocculation model recalled in Sections 1 and 2, we have simulated the behaviour of two different asphaltenic crudes PM1 and PM2 in reservoir conditions. These two bottom hole samples have been extensively studied previously, both with a constant mass/composition depletion and with a flocculation experiment as a function of pressure. All the measurements performed allow us to characterize each fluid as just described. Knowing the experimental behavior of these two crudes, we have carried a study hereafter with the aim of defining some basic assumptions regarding in situ flocculation in reservoirs.

Then these assumptions will be used to propose a simplified flocculation model which can be easily integrated in an industrial reservoir simulator.

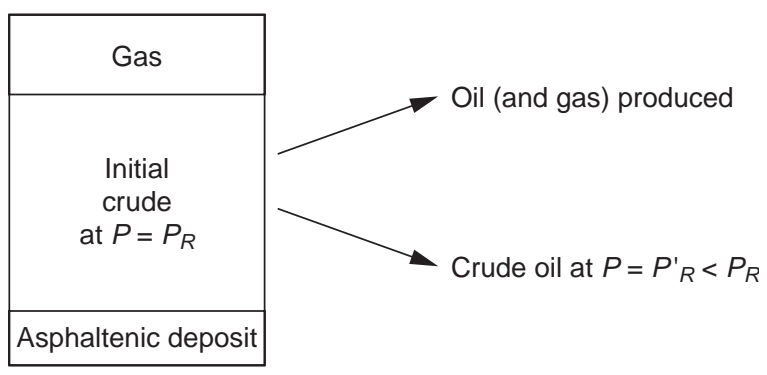

Figure 6

Simulation of a differential depletion.
In order to simulate the in situ flocculation of asphaltenic crudes in a reservoir, we have to consider the fact that pressure depletion results from a differential evolution. Figure 6 illustrates the type of modeling needed to represent such real conditions.

To perform these simulations, we assume that when the reservoir pressure is below the crude bubble pressure, the differential depletion comes mainly from gas production. With this assumption, each crude at a given pressure contains the same amount of asphaltenes as the initial reservoir oil, the deposits thus computed which would result from the differential depletion correspond therefore to maximum estimates.

Figures 7 and 8 show a comparison between the computed weight percent of asphaltenes flocculated when pressure is decreased, either by a constant mass expansion (CME) process or by a differential depletion (DD) process. Figure 7 corresponds to a crude having a bubble pressure of $21 \mathrm{MPa}$ while the oil PM2, for which the results are reported in Figure 8, has a much lower bubble pressure. However this last crude starts flocculating at high pressure as soon as the reservoir is depleted.

From these figures it appears that both constant mass expansion and differential depletion lead to very close amounts of flocculated asphaltenes for relatively different types of crudes. From the comparison of the ratio of weight percents of flocculated asphaltenes, computed by following the two depletion procedures for a set of crudes having GasOil Ratios within the range 44 to $160 \mathrm{~m}^{3} / \mathrm{m}^{3}$, it appears that differential depletion leads to equal or higher amounts of asphaltene deposits than constant mass/composition expansion. However the difference between the deposit amounts 


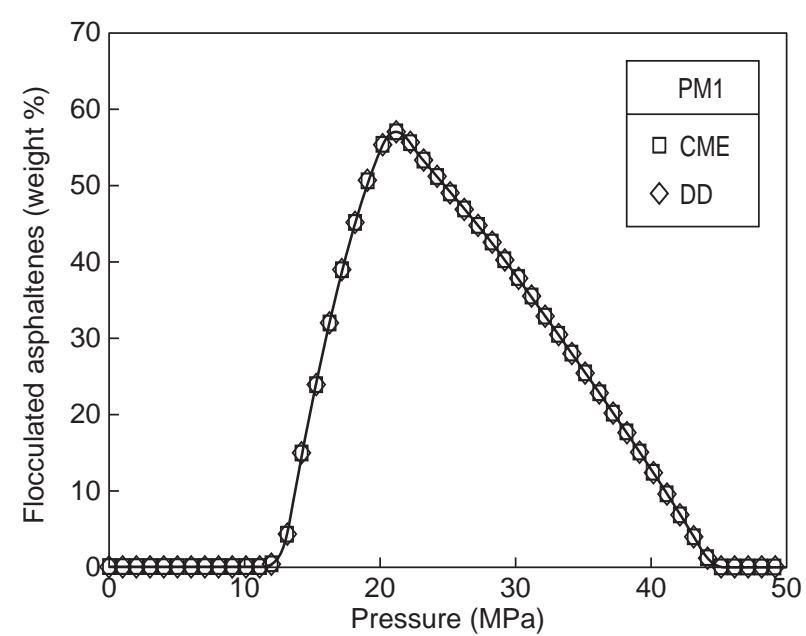

Figure 7

Comparison between the computed evolution of the amount of flocculated asphaltenes either by a CME process or by a DD process for reservoir crude PM1.

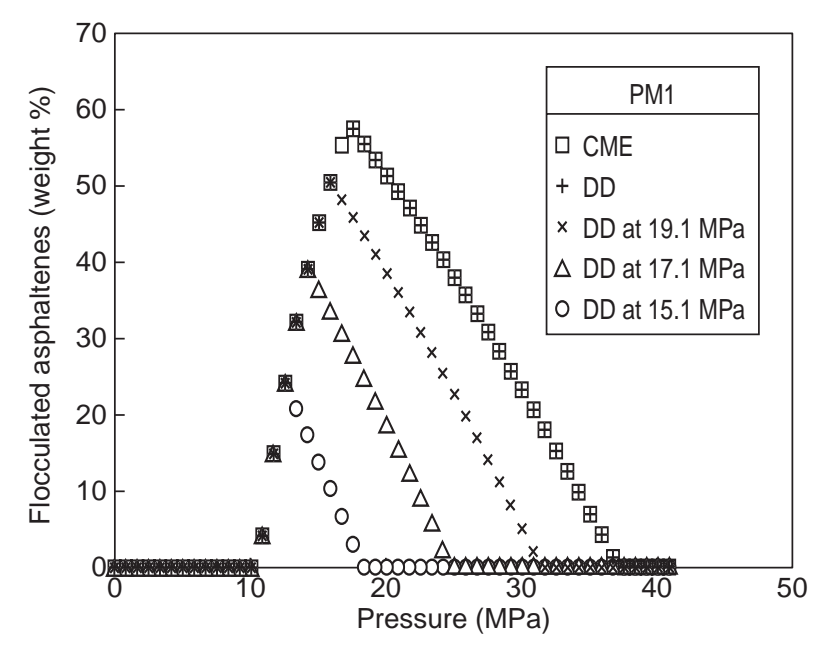

Figure 9

Computed evolution of the amount of flocculated asphaltenes by crudes recompression starting from different pressure levels below the $P_{b}$ of the original reservoir oil for crude PM1.

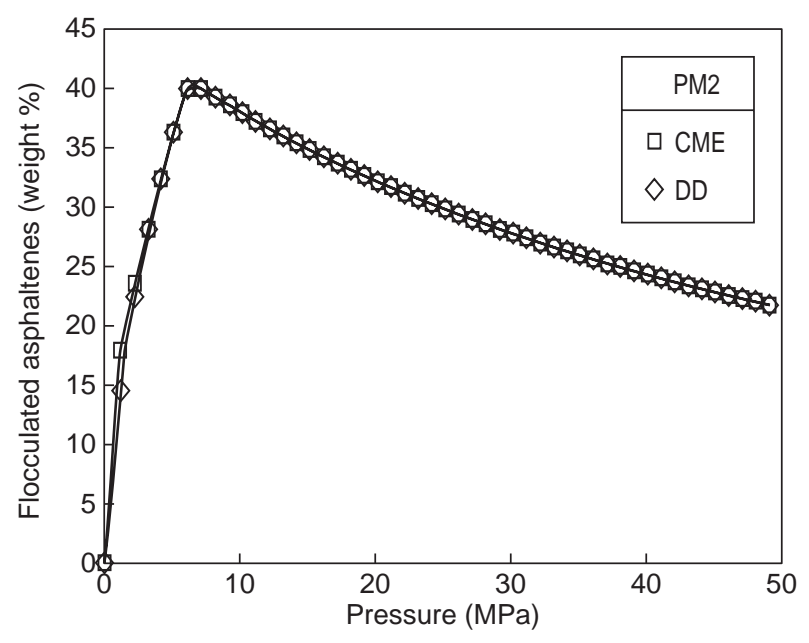

Figure 8

Comparison between the computed evolution of the amount of flocculated asphaltenes either by a CME process or by a DD process for reservoir crude PM2.

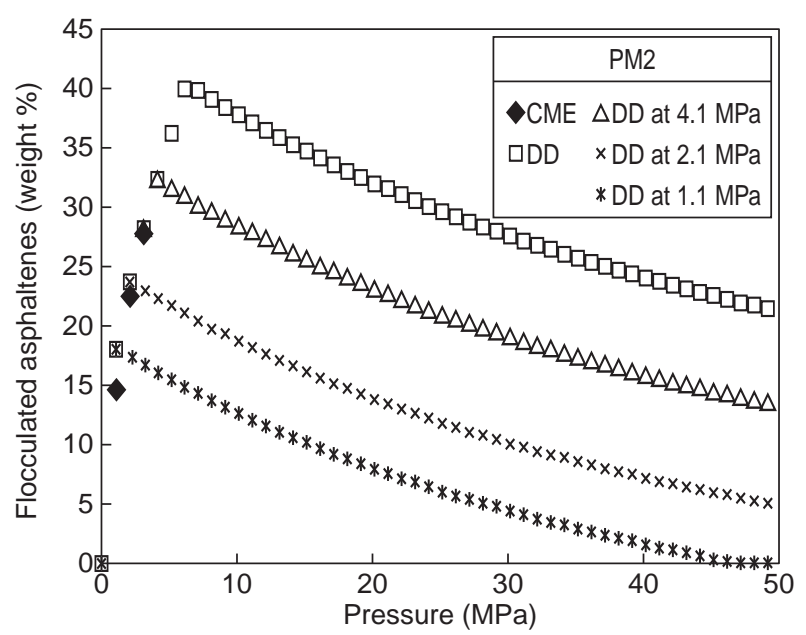

Figure 10

Computed evolution of the amount of flocculated asphaltenes by crudes recompression starting from different pressure levels below the $P_{b}$ of the original reservoir oil for crude PM2. resulting from these two kinds of depletion is always low. The explanation of such observations can be deduced from the detailed compositional analysis of the studied crudes, but needs to be confirmed with a larger set of oils.

Another application of this flocculation model is to consider the recompression of a depleted asphaltenic crude without any gas injection, i.e. only by water injection. Figures 9 and 10 show the results obtained for oils PM1 and PM2. On each of these figures, the different curves correspond to constant mass/composition expansion (CME), to differential depletion (DD) and to the recompression of crudes from which the gas has been produced at different pressure levels below the bubble point of the original reservoir oil. All these results relate to fluid mixtures having the same asphaltenes content, as only some of the gaseous components have been withdrawn from the system investigated.

These figures emphasize that the re-dissolution of asphaltenic deposits resulting from recompression occurs at lower 
pressures when gas has been produced at such pressure values. This comes from the fact that the lighter paraffinic components have been withdrawn from the malthenes phase thus increasing its solvent power.

\section{SIMPLIFIED FLOCCULATION MODEL TO BE INCLUDED IN A RESERVOIR SIMULATOR}

Let us consider a curve giving the amount of asphaltenes flocculated out of a crude versus pressure. This crude can thus be characterized by the maximum amount of flocculated asphaltenes at the bubble pressure as well as by two particular pressure values: the (high) pressure at which flocculation starts and the (low) pressure at which deposited asphaltenes re-dissolve in the crude.

For the simplified flocculation model, we have to keep in mind these three parameters. In a reservoir simulation, started with an initial oil composition, there are a lot of derived fluids and we are concerned by their flocculation as a function of pressure. The basis of the proposed simplified model is to use the flocculation data of the initial reservoir oil and to create the data for the derived oils (hereafter called "son" oils) by homothetic rules using the following three parameters:

- the high threshold pressure at which flocculation starts;

- the low pressure at which deposited asphaltenes re-dissolve;

- the maximum fraction of flocculated asphaltenes defined by the ratio between the maximum amount of flocculated asphaltenes and the total amount of asphaltenes in solution.

Let us show now how we propose to generate the flocculation curve of a "son" oil. If the pressure value $P$ is above the bubble point and below the flocculation threshold, the "father" oil will lead to an asphaltenic deposit and to a "son" crude. If no asphaltenes are in contact (added) to this "son" oil, its flocculation threshold is the pressure $P$. Assuming that the asphaltenes content does not affect the bubble pressure of a crude, both the "father" and "son" oils have the same bubble point. It is now possible to estimate the maximum fraction of flocculated asphaltenes for this "son" crude by following two possible procedures.

The simpler one is to write:

$$
\begin{gathered}
\text { max. fraction (weight \%) } \\
=100 \times \frac{\text { max. floc. amount "father" crude }- \text { floc. amount }}{\text { total asph. "father" crude }- \text { floc. amount }}
\end{gathered}
$$

In this relation, we have introduced the total amount of asphaltenes in the "father" crude, the maximum flocculated amount for the "father" oil and its flocculated amount at the pressure $P$.

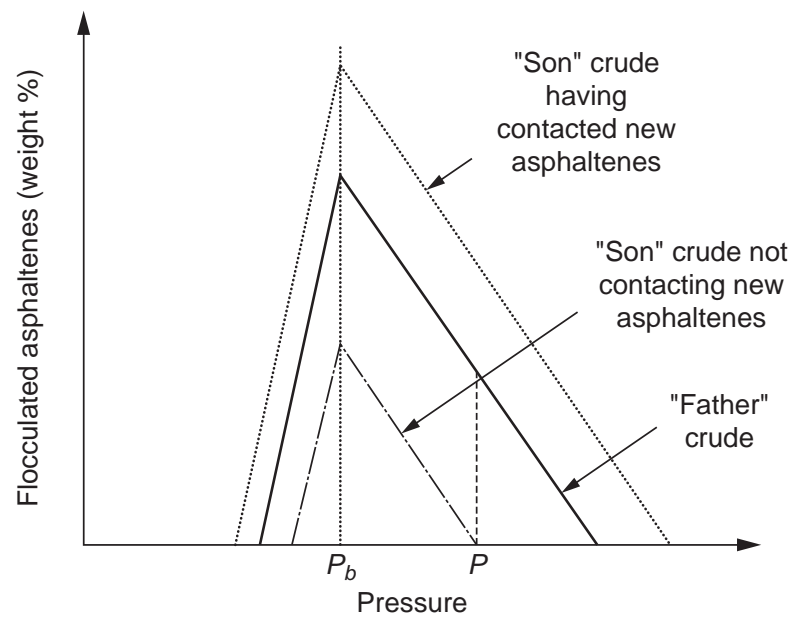

Figure 11

Computed evolution of the amount of flocculated asphaltenes for an original reservoir oil at a pressure higher than $P_{b}$ ("father") and the same oil after depletion ("son"), the latter having contacted or not an asphaltenic deposit.

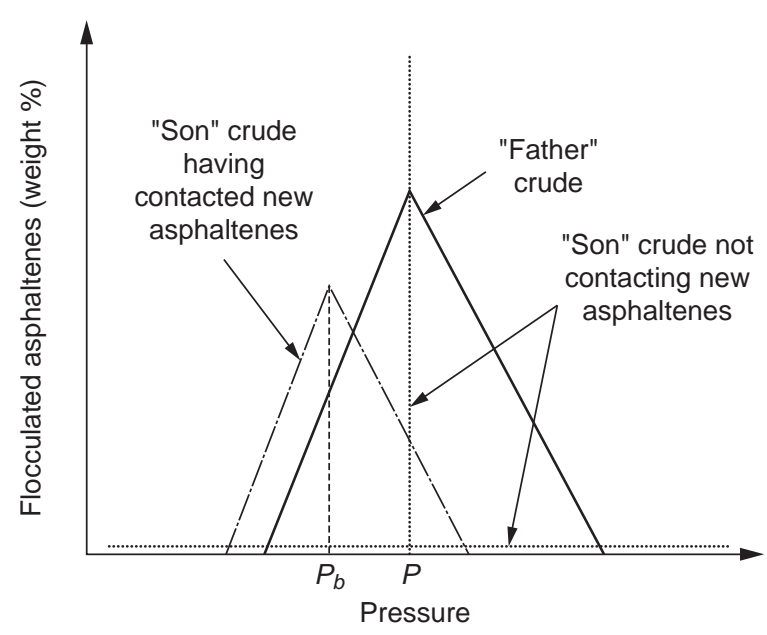

Figure 12

Computed evolution of the amount of flocculated asphaltenes for an original reservoir oil ("father") and the same oil after depletion ("son") at a pressure lower than $P_{b}$, the latter having contacted or not an asphaltenic deposit.

The second procedure assumes that the slope of the curve giving the amount of flocculated asphaltenes versus pressure is the same for both the "father" and "son" oils. Thus:

max. fraction (weight \%)

$=$ max. floc. amount "father" crude-floc. amount. 
In a reservoir simulator, the "son" crude flowing from a grid towards the well can come in contact with an asphaltenic deposit (new asph.) in another grid. In this case, the maximum fraction of flocculated asphaltenes can be determined by:

$$
\begin{aligned}
& \text { max. fraction (weight \%) } \\
& \text { max. floc. amount "father" crude-floc. amount } \\
& =100 \times \frac{+ \text { new asph. }}{\text { total asph. "father" crude }- \text { floc. amount }}
\end{aligned}
$$

Under these conditions, the new flocculation threshold pressure is obtained by keeping for the flocculation curve the slope corresponding to the "father" oil. Figure 11 illustrates all the above description. For pressures below the bubble point, we can simply consider a homothetical curve starting from the coordinates $\left(P_{b}\right.$, max.).

Let us consider now the case where oil and gas production occurs at a pressure value lower than the bubble point. Thus, the "son" crude has a bubble pressure equal to this (production) value. If this oil does not contact any asphaltenes, no flocculation will occur for all pressures above its bubble point. As pressure reduction below this bubble point will induce the transfer in the gas phase of the light paraffinic components which favor flocculation, the remaining liquid will have a better solvent power for its asphaltenes.

In the case that this "son" crude gets in contact with already flocculated asphaltenes, the maximum deposit fraction corresponding to its bubble pressure will be:

$$
\begin{gathered}
\text { max. fraction (weight \%) } \\
=100 \times \frac{\text { new asph. }}{\text { soluble asph. }+ \text { new asph. }}
\end{gathered}
$$

In order to find the flocculation threshold, we consider that the slopes of the deposition curves are the same for both the "father" and the "son" crudes. Figure 12 illustrates these last two cases.

Figures 11 and 12 show that a simplified flocculation model, to be included in a reservoir simulator such as Athos, can be "deduced" from a compositional model by using two parameters:

- the maximum fraction of flocculated asphaltenes for the initial reservoir crude;

- the slope of the flocculation curve as experimentally determined for this oil.

\section{CONCLUSIONS}

In order to improve the quality and the versability of the Athos reservoir simulator, it has been decided to integrate into it an asphaltenes flocculation model. The targets of such a model are to determine, as reliably as possible, the operating conditions which can lead to asphaltenes deposition, either inside the reservoir or in the production facilities.

The change in initial operating conditions can result:

- from pressure depletion related to oil (and gas) production;

- from composition variation related to oil in a (reservoir) grid coming into contact with already deposited asphaltenes in another grid, or from mixing crudes being produced from different reservoirs.

Figure 13 presents a schematic diagram of the procedures described above for computing (possible) asphaltenes flocculation when using a reservoir simulator.

Following procedure I, the experimental data available for the "reference" fluid (initial reservoir crude or "father" oil) are used to tune the parameters of the compositional flocculation model. It is then possible to generate the compositions of the different "son" fluids obtained after production of a part of the "reference" crude. From these compositions, the use of the compositional model will give the flocculation curves of these "son" oils.

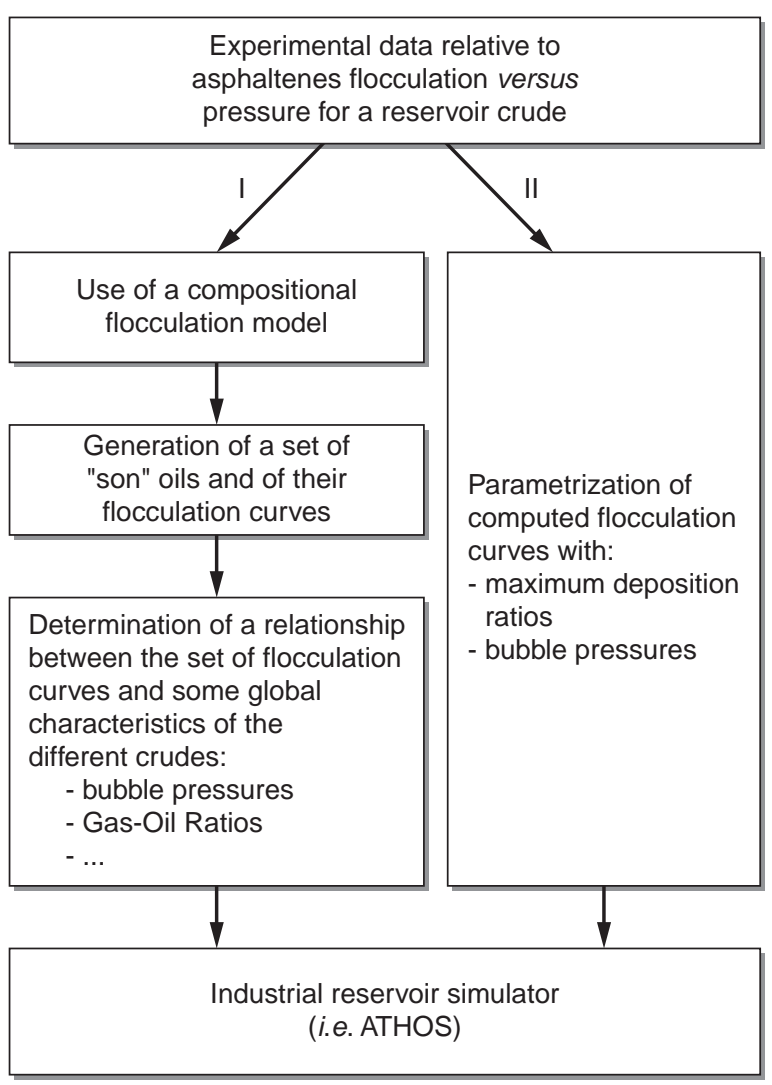

Figure 13

Schematic diagram showing the possible procedures (detailed I and simplified II) for computing asphaltenes flocculation when using a reservoir simulator. 
The next step while following procedure I will be to determine the relationship existing between the whole set of flocculation curves, both for the initial reservoir crude and its "son" oils and some of their global characteristics (i.e. some functions between the deposition curves and bubble pressures, Gas-Oil Ratios, etc.).

Procedure II relies on the observation that for different crudes coming form various reservoirs, the set of flocculation curves related to the initial oil and its associated "son" fluids can be characterized by two parameters: the maximum fraction of deposited asphaltenes and the corresponding bubble pressure.

This procedure can be easily integrated in a reservoir simulator such as Athos when no detailed compositional information is available on the studied crude ("black oil" type modeling).

In all cases, the only experimental information needed to compute within the reservoir simulator (possible) asphaltenes deposition occurrence is a flocculation curve versus pressure for the initial "reference" or "father" crude.

It is thus possible to determine the amount of asphaltenes deposit at different stages of a reservoir or of a field development. This would obviously improve the knowledge of porosity and permeability variations as a result of asphaltenes flocculation, and thus lead to better and more reliable prediction of the oil production.

\section{REFERENCES}

Abdoul, W., Rauzy, E. and Péneloux, A. (1991) Fluid Phase Equilibria, 68, 47-72.

API Technical Data Book (1983) Petroleum Refining, 4th ed. Avaullée, L. (1996) PhD Thesis, University of Aix-Marseille III.

Magras, J.F., Quandalle, P. and Bia, P. (2001) SPE Reservoir Simulation Symposium, Houston, Texas, SPE 66342. February 11-14.

Péneloux, A., Abdoul, W. and Rauzy, E. (1989) Fluid Phase Equilibria, 47, 115-132

Reid, R.C., Prausnitz, J.M. and Sherwood, T.K. (1987) The Properties of Gases and Liquids, $3^{\text {rd }}$ ed., Mac Graw Hill, New York.

Rogalski, M. and Neau, E (1990) Fluid Phase Equilibria, 56, 59-65.

Szewczyk, V. and Behar, E. (1999) Fluid Phase Equilibria, 158-160, $459-469$.

Final manuscript received in October 2003 